Japan-Bibliografie/Bibliography of Japan

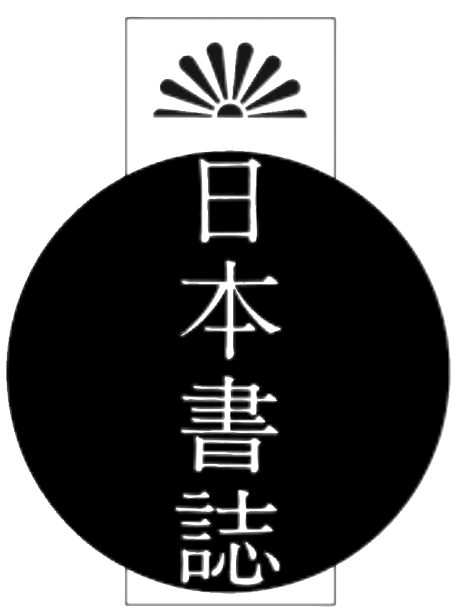



Wolfgang Hadamitzky / Marianne Rudat-Kocks

\author{
Japan-Bibliografie \\ Verzeichnis deutschsprachiger \\ japanbezogener Veröffentlichungen
}

Reihe B: Aufsätze

Band 2/ Teil 2: 1931-1937

\title{
Bibliography of Japan
}

German-language Publications on Japan

Series B: Articles

Volume 2/ Part 2: 1931-1937

$\mathrm{K} \cdot \mathrm{G} \cdot$ Saur München 2008 
Gestaltung des Emblems:

Yves Grauer, Berlin

Manfred Link, München

Zum Andenken an

Herrn Dr. Thilo Graf Brockdorff

1985-1998 Generalsekretär

des Japanisch-Deutschen Zentrums Berlin,

langjähriger Förderer der Japan-Bibliografie

Bibliografische Information der Deutschen Nationalbibliothek

Die Deutsche Nationalbibliothek verzeichnet diese Publikation

in der Deutschen Nationalbibliografie; detaillierte bibliografische Daten sind im Internet über http://dnb.d-nb.de abrufbar.

Bibliographic information published by the Deutsche Nationalbibliothek

The Deutsche Nationalbibliothek lists this publication in the Deutsche Nationalbibliografie; detailed bibliographic data are available in the Internet at http://dnb.d-nb.de.

Gedruckt auf säurefreiem Papier

Printed on acid free paper

(C) 2008 by K. G. Saur Verlag, München

Ein Imprint der Walter de Gruyter GmbH \& Co. KG

Printed in Germany

Alle Rechte vorbehalten / All rights strictly reserved

Das Werk ist in allen seinen Teilen urheberrechtlich geschützt.

Jede Verwertung ist ohne Zustimmung des Verlages unzulässig.

Das gilt insbesondere für Vervielfältigungen, Übersetzungen, Mikroverfilmungen und die Einspeicherung in und Verarbeitung durch elektronische Systeme.

No part of this publication may be reproduced, stored in a retrieval system, or transmitted in any form or by any means, electronic, mechanical, photocopying, recording, or otherwise, without permission in writing from the publisher.

Printed and bound by / Druck und Bindung: Strauss GmbH, Mörlenbach

978-3-598-22145-3 (Set)

978-3-598-22151-4 (Band 2/Teil 2) 